\title{
Sol-gel alumina coating on quartz substrate for environmental protection
}

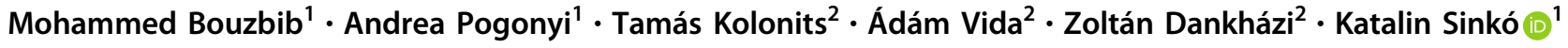

Received: 6 August 2019 / Accepted: 13 November 2019 / Published online: 3 December 2019

(c) The Author(s) 2019

\section{Abstract}

Transparent $\gamma-\mathrm{Al}_{2} \mathrm{O}_{3}$ thin film can be utilized as an absorbent or protective layer in environmental protection. The aim of the present research work is to improve the structural and optical properties of $\gamma-\mathrm{Al}_{2} \mathrm{O}_{3}$ thin film. $\mathrm{Al}_{2} \mathrm{O}_{3}$ thin films were synthesized by various newly developed routes based on colloidal technique and sol-gel chemistry. Many types of starting materials ( $\mathrm{Al}$ acetate, nitrate, isopropoxide, boehmite, and $\mathrm{Al}_{2} \mathrm{O}_{3}$ powders) and additives (acetic acid, $\mathrm{HCl}, \mathrm{HNO}_{3}$, citric acid) were used in the experiments. Suspension and gel-like precursor systems were compared for layer creation. The layers were characterized by their morphology (GIXRD), surface and thickness (SEM), as well as transparency (UV-visible spectroscopy). The best quality of layer ( $\sim 90 \%$ transmittance, $50-60 \mathrm{~nm}$ thickness, perfect covering) has been obtained by sol-gel technique starting from $\mathrm{Al}$ nitrate or $\mathrm{Al}$ acetate.

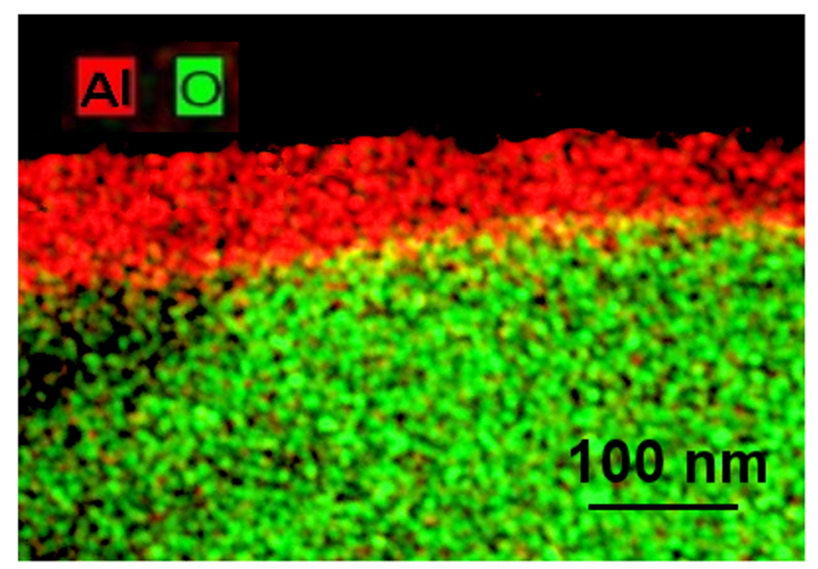

\section{Highlights}

- Various synthesis routes have been newly developed for $\gamma-\mathrm{Al}_{2} \mathrm{O}_{3}$ nanolayer preparation, which are based on colloidal technique and sol-gel chemistry.

- The best nanolayer can be obtained by sol-gel technique starting from Al nitrate or Al acetate.

- Comparing the application of colloidal suspensions (sol or slurry) with gel-like systems for layers creating, the gel-like systems results in better layers quality.

- The 3D network of the gel systems ensures the formation of a continuous film and allows the exact regulation of the layers thickness.

Katalin Sinkó

sinkokatl@caesar.elte.hu

1 Institute of Chemistry, Loránd Eötvös University, Budapest H1117, Hungary
Institute of Physics, Loránd Eötvös University, Budapest H-1117, Hungary 
Keywords Aluminum oxide $\cdot$ Protective coating $\cdot$ Sol-gel synthesis $\cdot$ Thin layer

\section{Introduction}

Aluminum oxide $\left(\mathrm{Al}_{2} \mathrm{O}_{3}\right)$ thin films have received a great attention due to their high transparency, wide band gap, chemical, and thermal stability. The alumina films may be transparent in ultraviolet, visible, and near infrared regions. Their durability against hostile environments and high transparency down to $200 \mathrm{~nm}$ enable the alumina layers to use in environmental protection. The $\gamma-\mathrm{Al}_{2} \mathrm{O}_{3}$ thin films can be applied as a protective layer in energyefficient compact fluorescent lamps [1]. The alumina layer protects the glass against the formation of sodium amalgam black pattern or $\mathrm{HgO}$ layer, since the blackening of the glass, which reduces the UV emission. In addition, the $\mathrm{Al}_{2} \mathrm{O}_{3}$ thin films have found wide applications in optoelectronics, microelectronics, wear resistant, catalysis applications [2-5], anticorrosive coatings [6, 7], and adsorption techniques [8].

There are several chemical and physical methods to synthesis aluminum oxide thin films, such as atomic layer deposition [9], chemical vapor deposition (CVD) [10-12], pulsed laser deposition [13], reactive magnetron sputtering [14], spray pyrolysis deposition [15], dip coating [16], and sol-gel route [17-30]. One of the most suitable processes for preparation of aluminum oxide thin films is the sol-gel technique due to its simplicity, cost-effectiveness, and ability to control the structure and texture properties [21]. The aluminum alkoxides such as aluminum isopropoxide and aluminum sec-butoxide are generally selected to prepare aluminum oxide thin film in sol-gel methods [22, 23]. A few organic stabilizers are employed to control the rate of hydrolysis of metal alkoxides and improve the quality and transparency of the thin films [24-26]. Yoldas prepared the first alumina thin films by sol-gel method applying $\mathrm{Al}$ alkoxide precursor in a very time-consuming process [27]. Inorganic $\mathrm{Al}$ salts such as nitrate and chloride are also applied in the sol-gel technique [28, 29]. Sol solutions have generally been prepared from inorganic Al salts and used as precursor systems of dip-coating process [30].

The aim of the present study was the comparison of $\gamma$ aluminum oxide thin films produced by various synthesis methods using different initial materials. The films were deposited by dip-coating technique. The structure of aluminum oxide thin films was investigated by grazing incidence X-ray diffraction (GIXRD) and scanning electron microscopy (SEM). The optical properties of layers were characterized by UV-visible spectroscopy regarding the requirements of the application as a protective layer in energy-efficient compact fluorescent lamps. The investigation of precursor systems was also aimed in order to determine which system is preferred for the layer formation; the suspensions (sol and slurry) or the gel-like system.

\section{Experimental section}

\subsection{Materials and syntheses}

\subsubsection{Layer from boehmite suspension}

A colloidal boehmite sol has been obtained by partial dissolution of boehmite powders (BASF) in acid medium. The most suitable acid medium is the aqueous solution of acetic acid (HAc). Boehmite powders were reacted with HAc in various molar ratios of $\mathrm{HAc}$ to $\mathrm{Al}: 0 ; 0.05 ; 0.1 ; 0.5 ; 1.0$; and 2.0. The reaction was carried out under stirring at $70{ }^{\circ} \mathrm{C}$ for $2 \mathrm{~h}$. The final sol concentration was also varied. IGEPAL solution was added to the every precursor system for the better sticking of layer on quartz substrate under ultrasonic condition [28].

\subsubsection{Layer from $\mathrm{Al}_{2} \mathrm{O}_{3}$ suspension}

An aqueous colloidal sol was prepared from $\mathrm{Al}_{2} \mathrm{O}_{3}$ powders. The sol was stirred for $2 \mathrm{~h}$ at $70{ }^{\circ} \mathrm{C}$. Various sol concentrations were used for layer procedures. The product of this preparation provides for the comparison as a commercial material of layer creation.

\subsubsection{Layer by sol-gel method starting from basic Al acetate}

The starting solution has been prepared by dissolving the aluminum acetate $\left(\mathrm{Al}\left(\mathrm{OCH}_{2} \mathrm{CH}_{3}\right)_{2} \mathrm{OH}, \mathrm{AlAc}\right)$ in $\mathrm{NaOH}$ solution in 0.11 molar ratio of $\mathrm{OH}$ to $\mathrm{Al}$ and heated at $55^{\circ} \mathrm{C}$ for $1 \mathrm{~h}$ under reflux. Various acids $(\mathrm{HCl}, \mathrm{HAc}$, and citric acid) were added to the basic solution in order to get $\mathrm{pH}=7$ and some fine and basic Al-containing precipitates.

In other sol-gel preparation route of layers, boehmite powders were also applied beside the basic aluminum acetate as initial materials. The aluminum acetate was separately dissolved in $\mathrm{NaOH}$ solution in molar ratio 0.11 and stirred at room temperature for $1 \mathrm{~h}$. The boehmite colloid solution was also separately prepared from boehmite powders with HAc in molar ratio 0.5 . The boehmite sol and 
the basic solution of $\mathrm{AlAc}$ were mixed in various ratios and heated at $55^{\circ} \mathrm{C}$ for $1 \mathrm{~h}$ under reflux.

\subsubsection{Layer by sol-gel method starting from Al nitrate}

Aluminum nitrate $\left(\mathrm{Al}\left(\mathrm{NO}_{3}\right)_{3} \cdot 9 \mathrm{H}_{2} \mathrm{O}\right.$, Aln $)$ was dissolved in 1-propanol in 0.12 molar ratio of $\mathrm{Al}$ to propanol. This solution was kept under stirring at $80^{\circ} \mathrm{C}$ for $15 \mathrm{~h}$. Hydrolysis and-with lower rate-condensation reactions take place during the heat treatment. The concentrated solution obtained by a partial evaporation of the solvent content supports the further condensation reactions. The viscous solution was dried at $80^{\circ} \mathrm{C}$. The product (a macroporous foam) could be swollen in distillated water in 5, 10, 20, and 40 mass ratios of water/solid material.

\subsubsection{Layer by sol-gel starting from Al isopropoxide}

Aluminum isopropoxide $\left(\mathrm{Al}\left(\mathrm{OCH}\left(\mathrm{CH}_{3}\right)_{2}\right)_{3}, \mathrm{AliPr}, 98 \%\right)$ was dissolved 1-propanol in 0.04 molar ratio of $\mathrm{Al}$ to propanol and stirred at $60^{\circ} \mathrm{C}$ for $2 \mathrm{~h}$. Ethyl acetate or HAc (as a peptizing agent) and water were added to the solution in 12.25 molar ratio of $\mathrm{Al}^{3+} / \mathrm{Ac}$ and 10 ratio of distilled water $/ \mathrm{Al}^{3+}$. The solution treated at $60^{\circ} \mathrm{C}$ for $3 \mathrm{~h}$. The obtained sol needs for further $24 \mathrm{~h}$ treatment to gain a gellike structure.

The other comparative precursor system was prepared by the widespread Yoldas's method [27]. According to this method, AliPr was dissolved in distilled water with molar ratio of 156 and stirred at $80^{\circ} \mathrm{C}$ for $1 \mathrm{~h}$. A slurry is formed. HAc is added to the slurry in 4.9 molar ratio of $\mathrm{Al}^{3+} / \mathrm{HAc}$. This system must be stirred at $80^{\circ} \mathrm{C}$ for $8 \mathrm{~h}$ in order to become a transparent sol solution from slurry.

In every sol-gel route, an IGEPAL solution was used as the nonionic surfactant for the better sticking of layer on quartz substrate. The quartz substrate was ultrasonically cleaned with acetone, ethanol, and deionized water and dried. Every layer was deposited by dip-coating technique. The concentration of precursor systems for coating was varied. All layers were dried at $70{ }^{\circ} \mathrm{C}$ for $1 \mathrm{~h}$ and then heated at $600{ }^{\circ} \mathrm{C}$ for $3 \mathrm{~h}$.

\subsection{Investigation methods}

\subsubsection{Transmittance measurements}

Transmittance measurements have been carried out on UV-VIS spectrophotometer (Dynamica equipment, UV Detective prog.) at room temperature, in the range of 190-300 nm.

\subsubsection{Grazing incidence X-ray diffraction (GIXRD)}

GIXRD measurements were performed by a Rigaku Smartlab X-ray diffractometer equipped with a $1.2 \mathrm{~kW}$ copper source (radiation wavelength: $\mathrm{CuK} \alpha ; \lambda=$ $0.15418 \mathrm{~nm}$ ). To reduce the effect of the substrate, a grazing incidence parallel-beam geometry was used with an incidence angle of $\omega=1^{\circ}$. Scans were performed in the range $2 \Theta$ between 10 and $110^{\circ}$ with a $1 \mathrm{D}$ silicon strip detector (D/ Tex ultra 250 ) by a speed $0.2^{\circ} / \mathrm{min}$.

$X R D$ measurements were carried out by using a Philips (PW1130) X-ray generator set up with a Guinier-chamber. The chamber has a diameter of $100 \mathrm{~mm}$ and the patterns were recorded on FUJI Imaging Plates (BAS MS2025). The XRD data were collected over the $2 \theta$ range of $9-90^{\circ}$ with a step size $0.005^{\circ}$. Identification of phases was performed by comparing the diffraction patterns with standard PDF cards.

\subsubsection{Scanning electron microscope (SEM)}

The surface covering and the layer thickness have been studied by the FEI Quanta 3D FEG scanning electron microscope (SEM). The SEM images were prepared by the Everhart-Thornley secondary electron detector, its ultimate resolution is $1-2 \mathrm{~nm}$. Since the conductance of the particles investigated is high enough to remove the electric charge accumulated on the surface, the SEM images were performed in high vacuum without any coverage on the specimen surface. For the best SEM visibility, the particles were deposited on an HOPG (graphite) substrate surface. SEM combined with energy disperse X-ray spectroscopy is applied for spatially resolved chemical analysis of layers.

\subsection{4 pH meter}

The $\mathrm{pH}$ has been measured by education line EL20 (Mettler-Toledo) calibrated with different buffer solutions of $\mathrm{pH}$ 4.01, 7.00, and 9.21.

\section{Results and discussion}

The main aim of the syntheses was to prepare $\gamma-\mathrm{Al}_{2} \mathrm{O}_{3}$ transparent nanofilms with good quality. The other aim was the investigation of precursor systems for layer formation in order to determine the more preferred precursor a suspension (sol and slurry) or a gel-like system. The sol or slurry systems contain separated particles in nano or micrometer ranges, respectively. The gel-like systems are built up from 


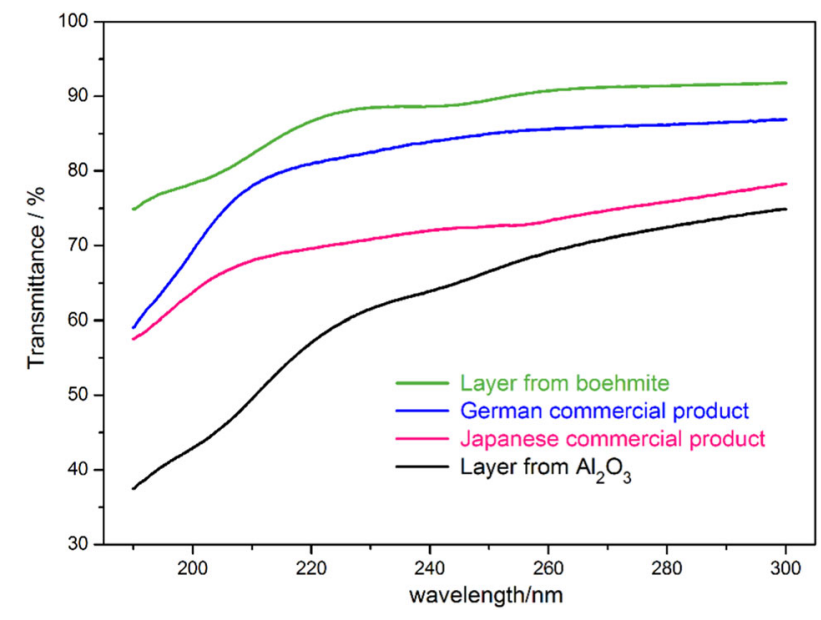

Fig. 1 Transmittance of layers prepared from boehmite and aluminum oxide suspensions and commercial $\mathrm{Al}_{2} \mathrm{O}_{3}$ layer products

3D network but the network does not perfectly fill the whole volume of the system. The gel-like system can be turned to continuous gel layer on the substrate.

\subsection{Layers from boehmite or $\mathrm{Al}_{2} \mathrm{O}_{3}$ suspension}

In the first experiments, the aqueous sol solutions of boehmite and $\mathrm{Al}_{2} \mathrm{O}_{3}$ provide as precursor system for dipcoating techniques. Regarding the transmittance data of UV-Vis spectroscopy in Fig. 1, the layer produced from boehmite sol possesses very good transparency, much higher than that of layer derived from $\mathrm{Al}_{2} \mathrm{O}_{3}$ sol. The commercial products of alumina layer provide the comparison of various layers.

HAc proved to be most efficient from the investigated acids $\left(\mathrm{HCl}, \mathrm{HNO}_{3}\right.$, and citric acid) in order to improve the layer quality. The HAc can attack and partly dissolve the boehmite particles reducing their size and enabling to from a thin layer. Moreover the acetate anions can connect two $\mathrm{Al}$ ions as a bidentate ligand represented in Fig. 2. The shared $\mathrm{OH}$ groups and the acetate bidentate ligands support and stabilize the formation of a continuous layer. The molar ratio of HAc has also been optimized in the precursor sol solution. The transmittance data are displayed in Figs. 3 and 4. The ideal molar ratio of HAc/Al was 0.50 . The larger HAc volume results in stronger acidity, which hinders the $\mathrm{OH}$ and acetate substitution and the condensation reactions.

The concentration of the initial sol solutions was also studied. The research data show in Fig. 5, the smaller the concentration of boehmite, the thinner the layer and the larger the transmittance are (Fig. 5). In order to determine the temperature, at which the boehmite transforms into $\gamma-\mathrm{Al}_{2} \mathrm{O}_{3}$, the boehmite sol particles were heated at various temperatures and measured by XRD (Fig. 6). The optimal

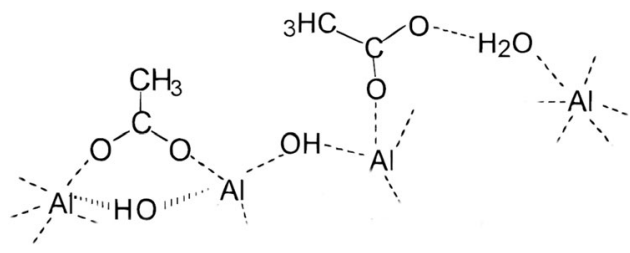

Fig. 2 The probable connections between the octa- and tetracoordinated $\mathrm{Al}$ ions on the surface of boehmite

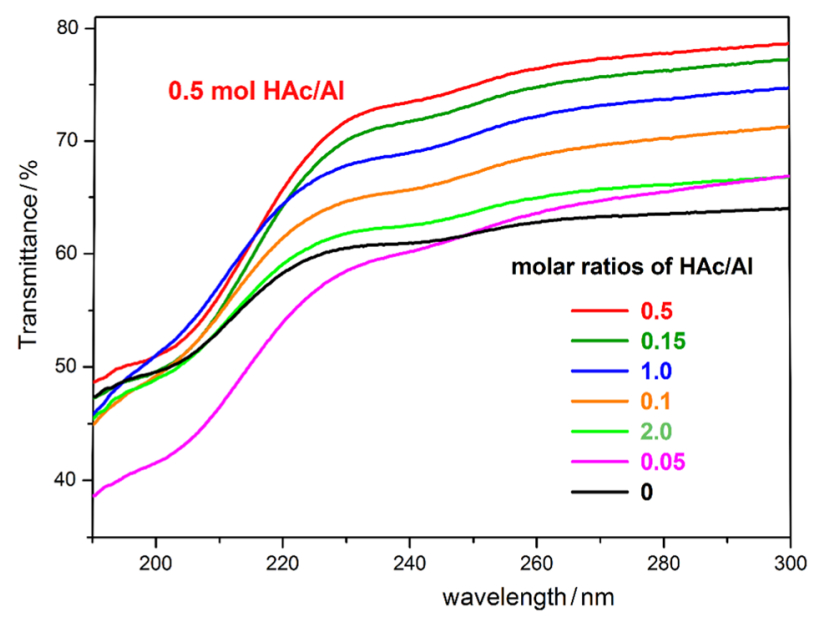

Fig. 3 Transmittance of layers prepared from boehmite sol in the function of acetic acid molar ratio

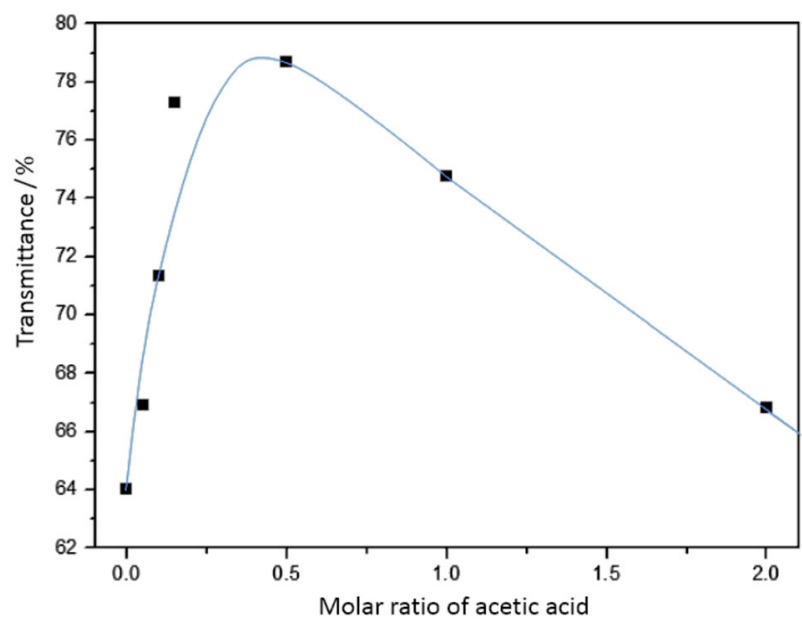

Fig. 4 Transmittance of layers prepared from boehmite sol in the function of acetic acid molar ratio

temperature of heat treatment is between 600 and $800{ }^{\circ} \mathrm{C}$ to develop $\gamma-\mathrm{Al}_{2} \mathrm{O}_{3}$.

The aim of SEM investigation shown in Fig. 7 was to control the surface coverage of quartz substrate and the thickness of layers. The layer derived from boehmite sol perfectly and homogeneously covers the substrate and layer's thickness is $110-120 \mathrm{~nm}$. The ideal preparation conditions: 0.5 molar ratio of $\mathrm{HAc} / \mathrm{Al}$ and $10 \mathrm{~g} / \mathrm{l}$ sol concentration. According to Fig. 8, the layer formed from 


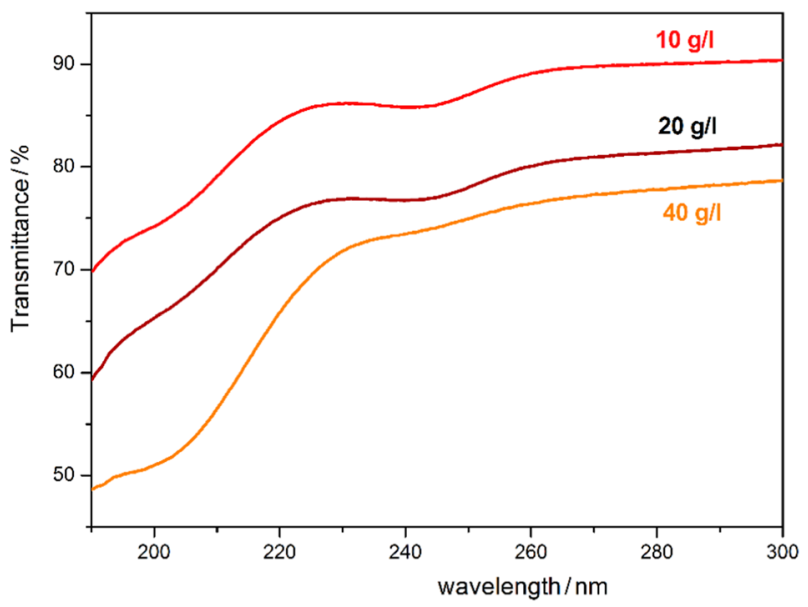

Fig. 5 Transmittance of layers in the function of concentration of boehmite sol prepared with 0.5 molar ratio of $\mathrm{HAc} / \mathrm{Al}$

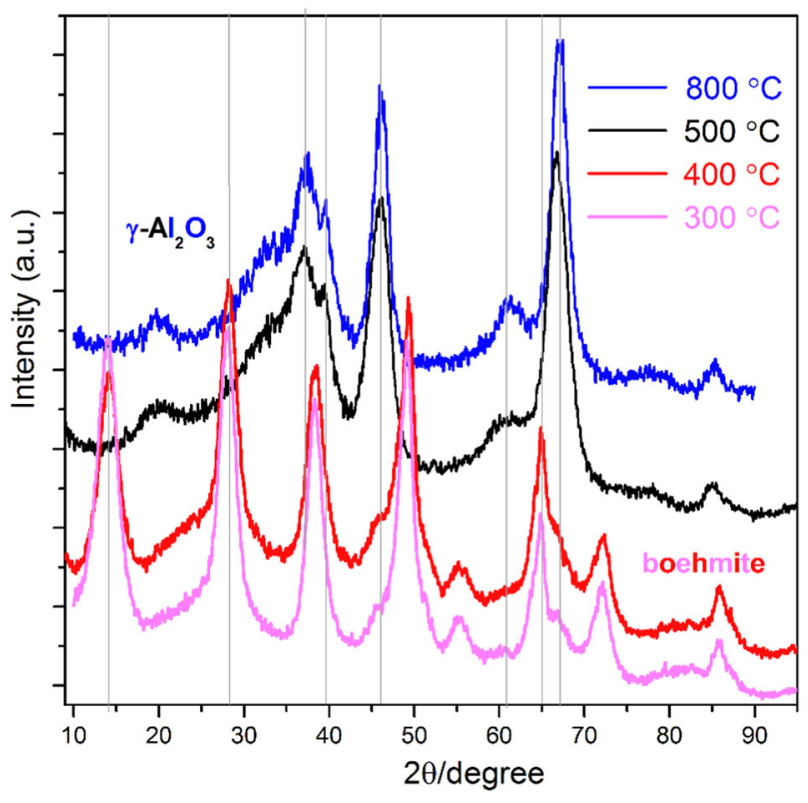

Fig. 6 XRD diffractions of böhmit vs. temperature
$\mathrm{Al}_{2} \mathrm{O}_{3}$ suspension is not so homogeneous, contains some particles of $\leq 1 \mu \mathrm{m}$. Its thickness is larger $(135-145 \mathrm{~nm})$ than that of layer of boehmite. Due to the thicker layer, its transmittance is less. Figure 9 reveals the results of EDAX investigation, the data confirm the presence of $\mathrm{Al}$ atoms in the layer of boehmite sol.

\subsection{Layer by sol-gel method starting from Al acetate (AIAC)}

In the sol-gel syntheses the starting materials (Al acetate, nitrate, and isopropoxide); acid catalyst ( $\mathrm{HCl}, \mathrm{HAc}$, citric acid, $\mathrm{HNO}_{3}$ ); their concentration; and additives (e.g. boehmite powder) were varied. The real novelties can be achieved by the application of $\mathrm{Al}$ acetate and nitrate. The use of $\mathrm{Al}$ isopropoxide provides for comparison.

The application of acetate anions can be particularly explained by environmental protection, during the heat treatment the acetate ions decompose into nontoxic $\left(\mathrm{CO}_{2}\right.$ and $\mathrm{H}_{2} \mathrm{O}$ ) molecules. In other respect, the acetate ions may have a role in the connection of $\mathrm{Al}$ atoms to other atoms as bidentate ligands.

As shown in Fig. 10, the transmittance values vigorously depends on the acid concentrations. The best transmittance value can be achieved at 2 molar ratio in the case of strong acid such as $\mathrm{HCl}$. In the treatment with weak acid (HAc), the molar ratio of 10 proved to be optimum value. The larger ratios than $10 \mathrm{~mol} \mathrm{HAc/Al}$ cannot further improve the transmittance. (See Fig. 11).

The gel-like system derived from $\mathrm{Al}$ acetate was subjected to treatment of various additives (e.g. citric acid or boehmite powders). The citric acid can coordinate to $\mathrm{Al}$ ions to support a continuous layer formation. The presence of boehmite powders initializes the development of gamma $\mathrm{Al}_{2} \mathrm{O}_{3}$ phase. The citric acid may be applied in maximum 1.0 molar ratio in this system, because the use of $>1.0$ ratio yields inhomogeneous layers. Figure 12 represents the effect of various acids with optimal ratio and the additives on the
Fig. 7 SEM images of $\mathrm{Al}_{2} \mathrm{O}_{3}$ layer obtained from boehmite suspension with 0.5 molar ratio of HAc/Al. Magnification: $\times 25,000 ; \times 100,000, \times 65,000$ $(110-120 \mathrm{~nm})$
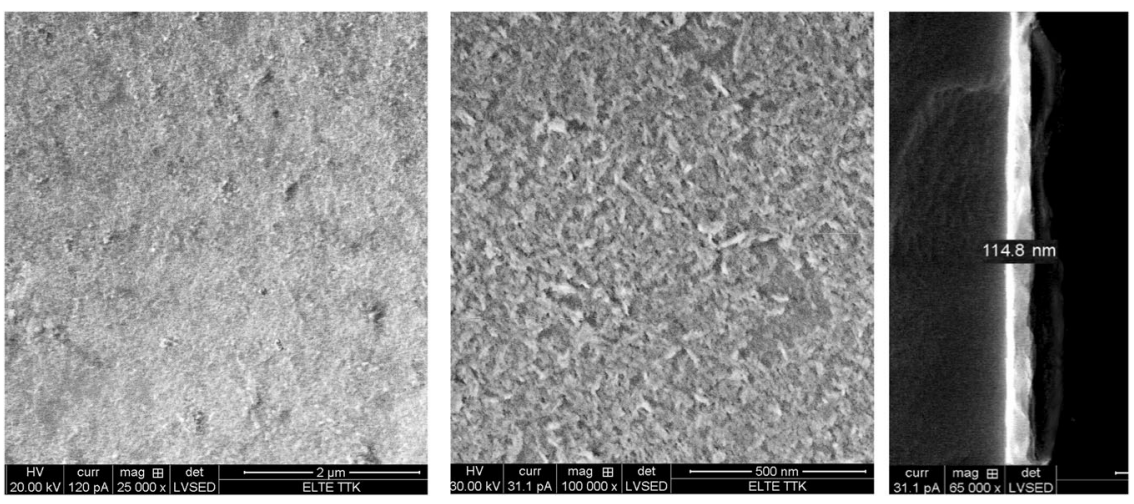
Fig. $8 \mathrm{SEM}$ images of $\mathrm{Al}_{2} \mathrm{O}_{3}$ layer obtained from $\mathrm{Al}_{2} \mathrm{O}_{3}$ suspension without HAc. Magnification: $\times 25,000$; $\times 100,000, \times 80,000$ $(135-145 \mathrm{~nm})$
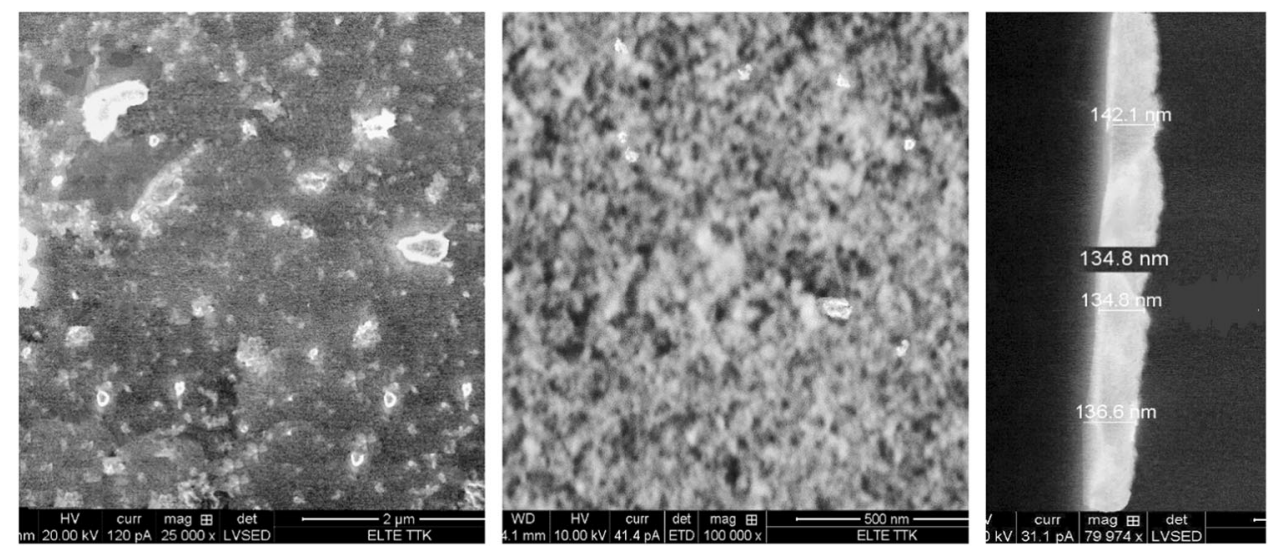

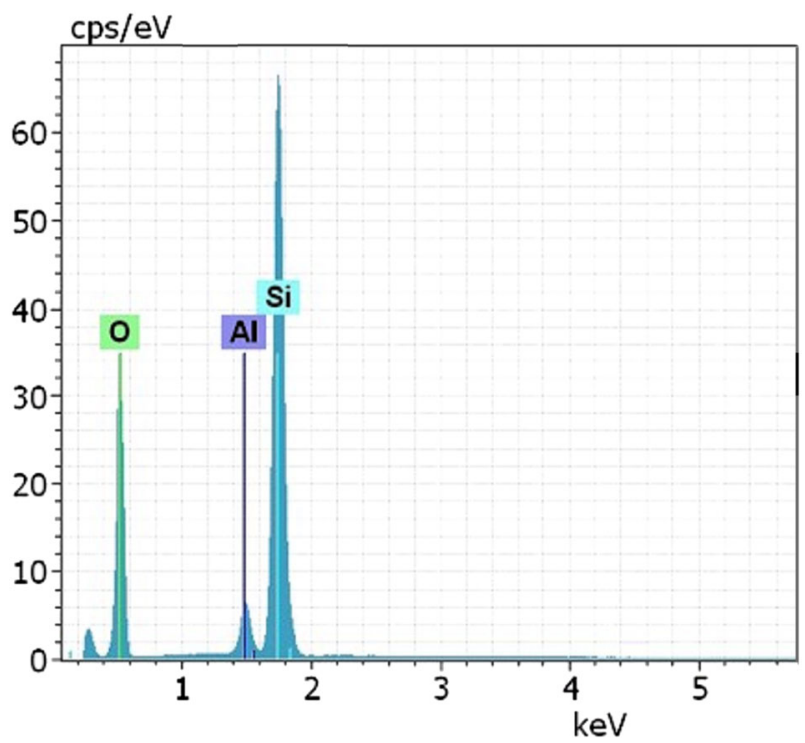

Fig. 9 EDAX measurement of $\mathrm{Al}_{2} \mathrm{O}_{3}$ layer obtained from boehmite suspension with 0.5 molar ratio of $\mathrm{HAc} / \mathrm{Al}$

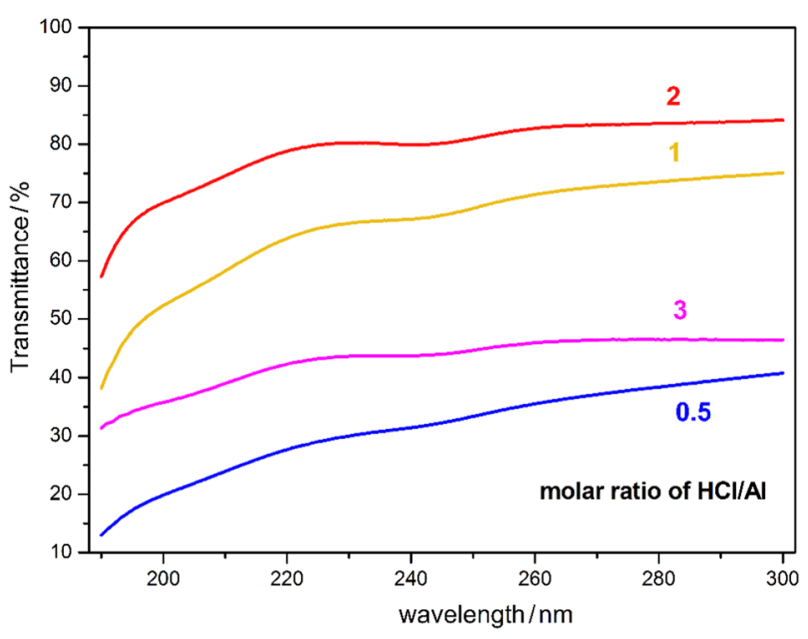

Fig. 10 Transmittance of sol-gel derived layers prepared from $\mathrm{Al}$ acetate in the function of $\mathrm{HCl}$

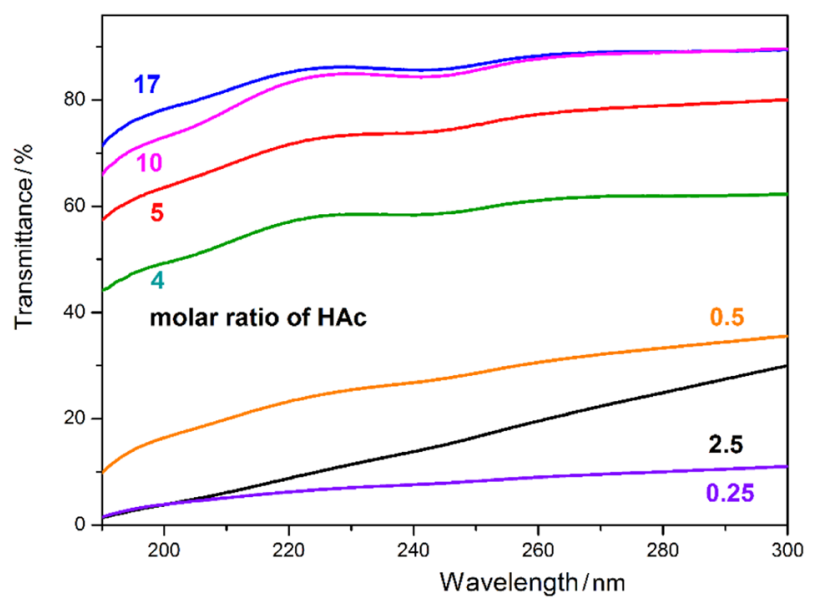

Fig. 11 Transmittance of sol-gel derived layers prepared from $\mathrm{Al}$ acetate in the function of acetic acid (HAc)

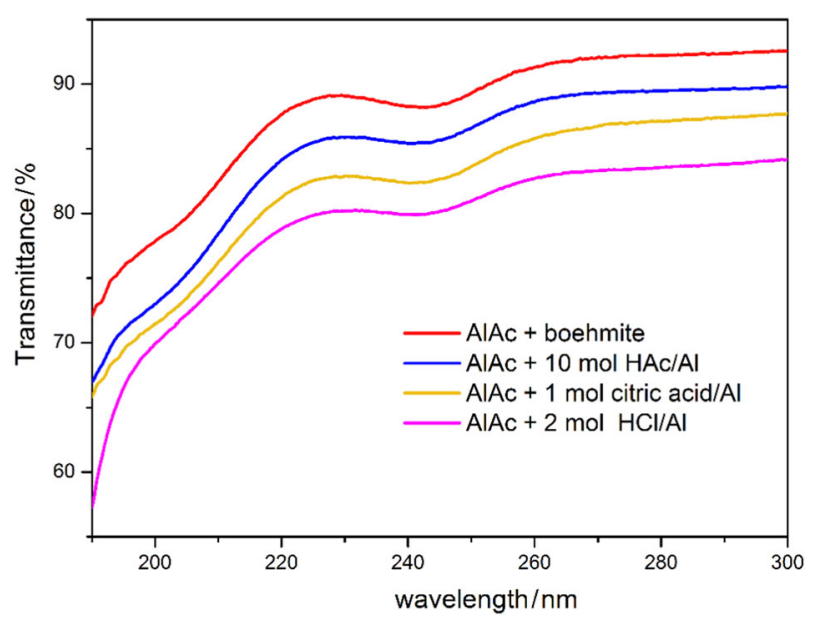

Fig. 12 Transmittance of sol-gel derived layers prepared from $\mathrm{Al}$ acetate $(\mathrm{AlAc})$ with various additives

transmittance. The layer prepared from $\mathrm{Al}$ acetate in the presence of boehmite possesses the best transmittance value. The mass ratio of $\mathrm{Al}$ acetate and boehmite powders was 1:1. 
Application of both acids and boehmite yields layers of gamma $\mathrm{Al}_{2} \mathrm{O}_{3}$ after a heat treatment at $600{ }^{\circ} \mathrm{C}$, it has been proved by Fig. 13. The evaluation of GIXRD spectra based on cards of JCPDS 29-0063 for $\gamma-\mathrm{Al}_{2} \mathrm{O}_{3}$, JCPDS 46-1215 for $\delta-\mathrm{Al}_{2} \mathrm{O}_{3}$, JCPDS 21-1307 for pseudo-
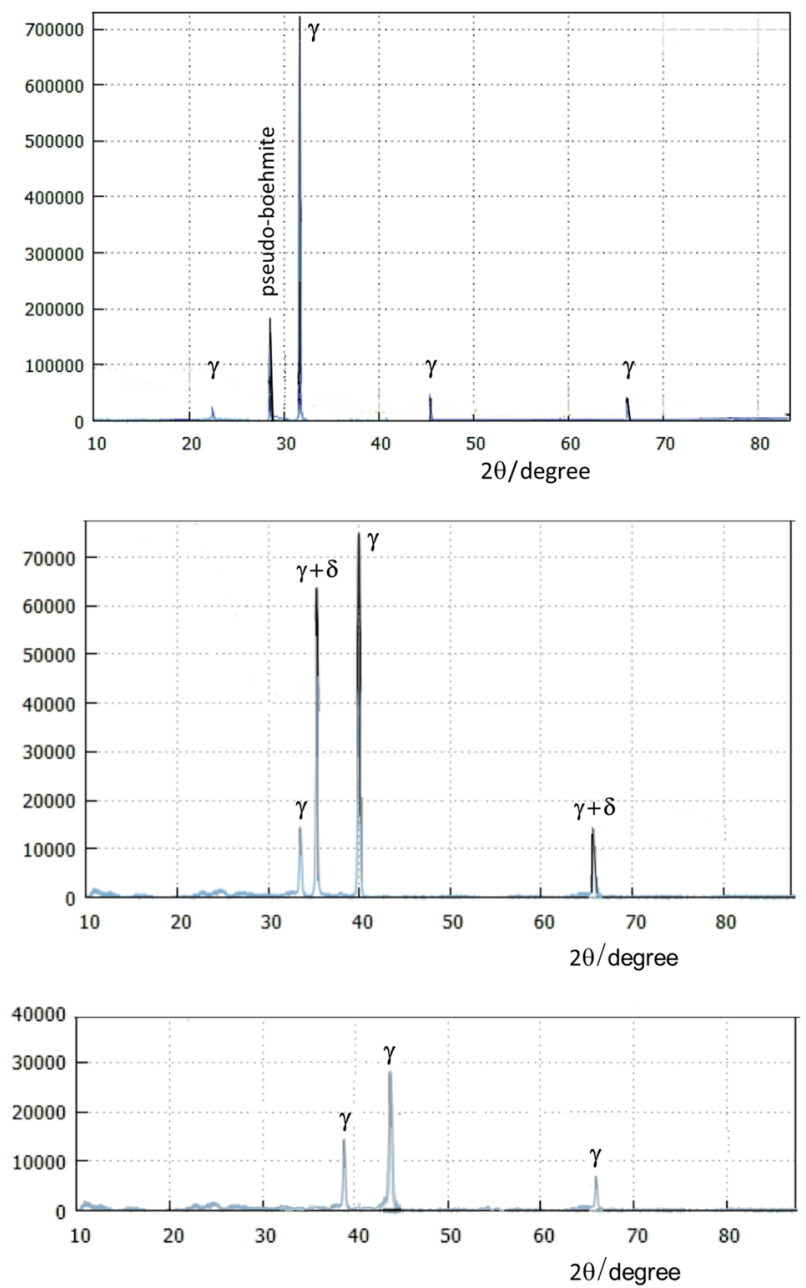

Fig. $13 \mathrm{XRD}$ spectrum of sol-gel derived $\mathrm{Al}_{2} \mathrm{O}_{3}$ layers prepared from $\mathrm{Al}$ acetate with $\mathrm{HCl}$ (upper), $\mathrm{HAc}$ (middle), and boehmit (lower) boehmite. In the respect of SEM images of Figs. 14-16, the layers produced from $\mathrm{Al}$ acetate in the presence of $\mathrm{HCl}, \mathrm{HAc}$, and boehmite, are continuous, cover well the quartz surface without any cracks. Figure 16 depicts the thinnest layer with $50-60 \mathrm{~nm}$ thickness obtained from common use of $\mathrm{Al}$ acetate and boehmite. The surface of this layer is similar to that of layer derived from single precursor boehmite.

\subsection{Layer by sol-gel method starting from Al nitrate}

Using $\mathrm{Al}$ nitrate precursor, the layer of best quality can be achieved by 20 mass ratio of water/dried gel. Further diluting is not able to produce continuous covers. The layer of Al nitrate shows excellent transmittance represented in Fig. 17. The layer has a continuous smooth surface without any cracks. (See in Fig. 18). Regarding its thickness $(55-65 \mathrm{~nm})$ that is also a nanofilm. After the heat treatment at $600{ }^{\circ} \mathrm{C}$ a slightly disordered $\gamma-\mathrm{Al}_{2} \mathrm{O}_{3}$ phase develops, however, the 100 peak of $\gamma-\mathrm{Al}_{2} \mathrm{O}_{3}$ is missing at $67^{\circ}$ in GIXRD diagram shown in Fig. 19. The use of $\mathrm{Al}$ nitrate precursor has only one disadvantage that is the escape of nitrous gases during the gelation process and heat treatment.

\subsection{Layer by sol-gel method starting from Al isopropoxide}

The experiments with $\mathrm{Al}$ isopropoxide (AliPr) result in not really perfect layer quality. By Yoldas synthesis a layer with respectable quality can be obtained; the layer thickness is $75-85 \mathrm{~nm}$ and the transmittance is sufficient. In respect of these results we tried to develop a new route starting from Al isopropoxide. But the layer quality obtained by our method was not sufficient comparing the layers obtained by other methods (Figs. 20-22). Regarding the quality of the layers and the price of AliPr, the application of AliPr was rejected.
Fig. 14 SEM of sol-gel derived layers prepared from $\mathrm{Al}$ acetate (AlAc) with $\mathrm{HCl}$. Magnification: $\times 25,000 ; \times 100,000, \times 80,000$.

Layer thickness is $130-150 \mathrm{~nm}$
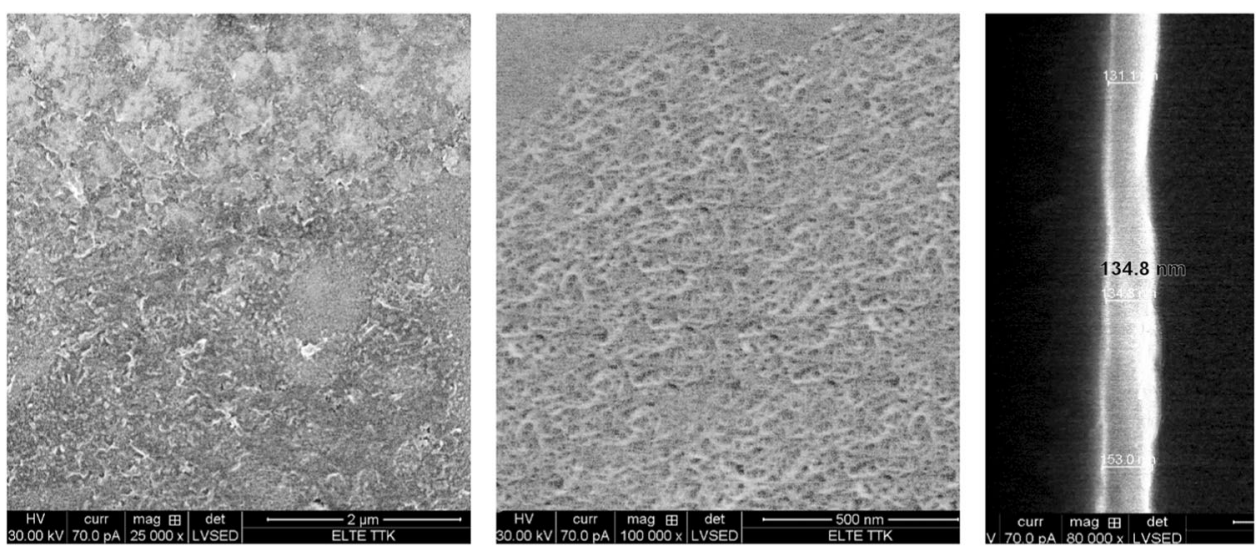
Fig. 15 SEM of sol-gel derived layers prepared from $\mathrm{Al}$ acetate (AlAc) with HAc

Magnification: $\times 15,000$; $\times 80,000, \times 100,000$. Layer thickness is $60-105 \mathrm{~nm}$
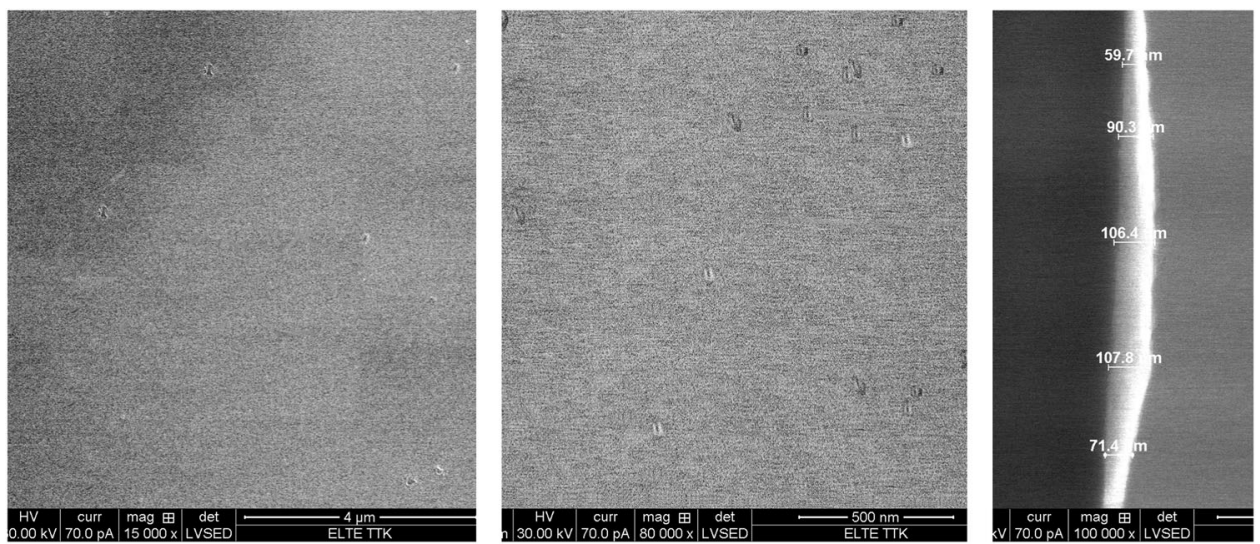

Fig. 16 SEM of sol-gel derived layers prepared from $\mathrm{Al}$ acetate (AlAc) with boehmite. Magnification: $\times 25,000$; $\times 100,000, \times 120,000$. Layer thickness is $50-60 \mathrm{~nm}$
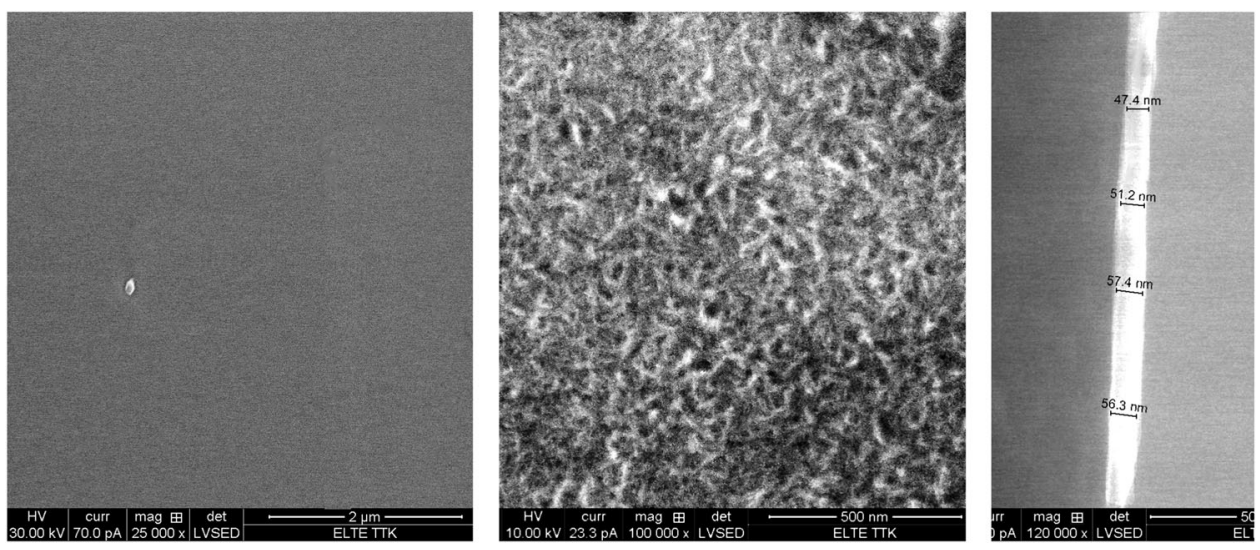

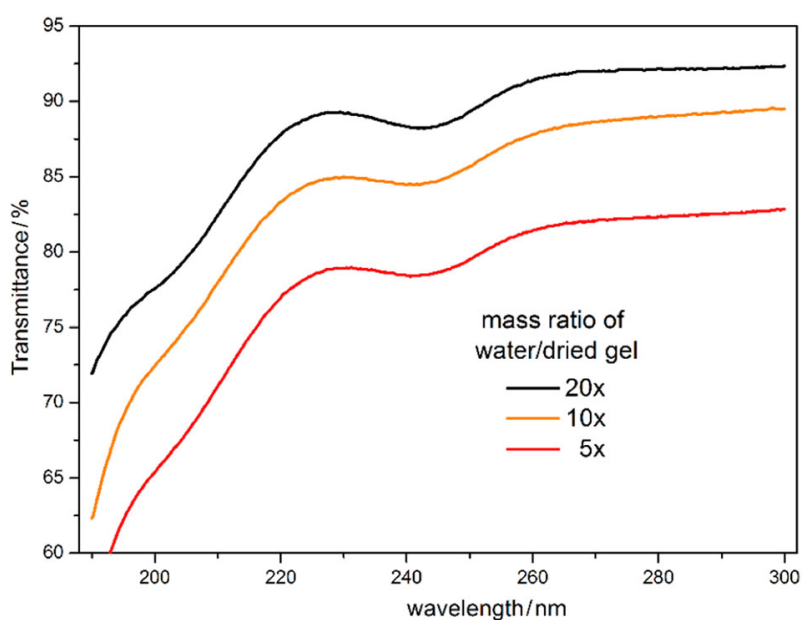

Fig. 17 Transmittance of sol-gel derived layers prepared from $\mathrm{Al}$ nitrate

\subsection{Comparison of $\mathrm{Al}_{2} \mathrm{O}_{3}$ layers prepared by various synthesis routes}

The next table aims to assist the comparison of the aluminum oxide layers by means of some layer parameters (Table
1). Two sol-gel syntheses result in the best layer quality: starting from $\mathrm{Al}$ acetate (using boehmite $+\mathrm{HAc}$ ) and $\mathrm{Al}$ nitrate (Table 1). These layers keep their protective character for long time, they were controlled in $500 \mathrm{~h}$ application.

$\mathrm{Al}$ acetate is the best initial materials due to its environmental friendly decomposition and the acetate ions support and stabilize the formation of continuous layers by connecting two $\mathrm{Al}$ ions as a bidentate ligand. HAc and boehmite powders as additives proved to be most efficient for the improvement of layer quality. HAc is capable partly dissolve boehmite powders and boehmite initializes the development of $\gamma-\mathrm{Al}_{2} \mathrm{O}_{3}$ phase.

Comparing the application of the colloidal suspensions (sol or slurry) with gel-like systems for layer creation, the gel-like systems proved to be more suitable. The 3D network of the gel systems developed on the substrates from gel-like precursors ensures the formation of a continuous film and allows to regulate the thickness of layers. However, the suspensions, especially the slurries are current precursor systems for covering but they generally yield thicker layers, which may not perfectly cover the surfaces owing to the presence of larger particles. 
Fig. 18 SEM of sol-gel derived layers prepared from $\mathrm{Al}$ nitrate. Magnification: $\times 25,000$; $\times 100,000, \times 120,000$. The layer thickness is $55-65 \mathrm{~nm}$
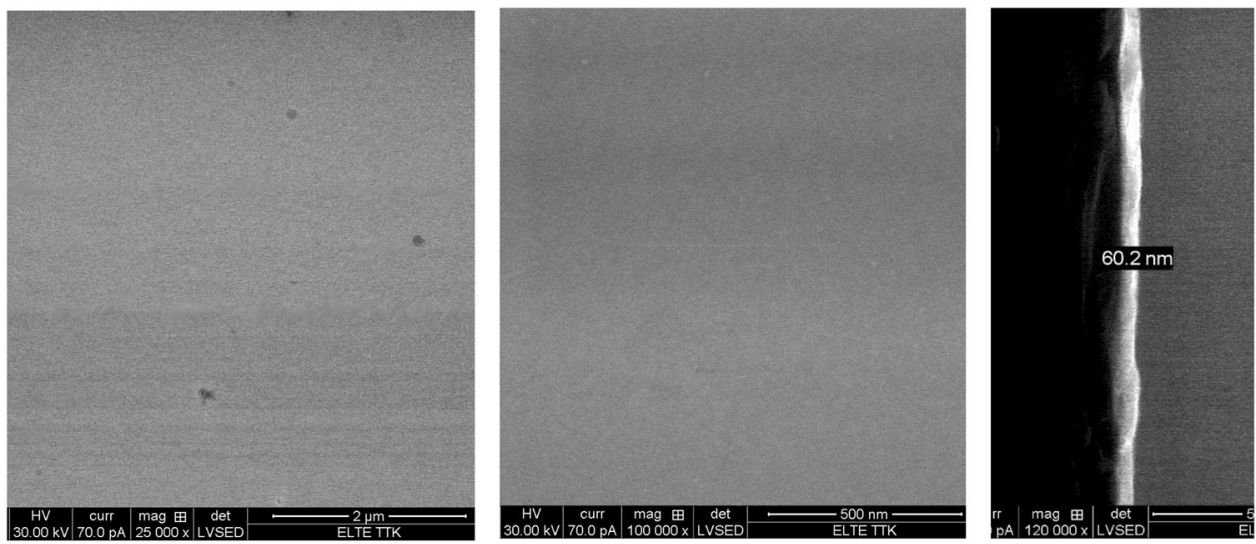

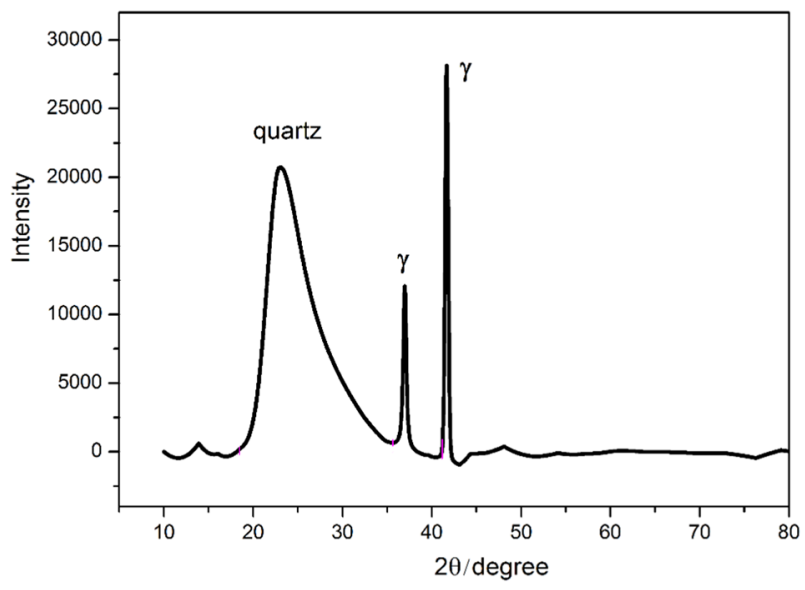

Fig. 19 GIXRD spectrum of sol-gel derived $\mathrm{Al}_{2} \mathrm{O}_{3}$ layers prepared from $\mathrm{Al}$ nitrate

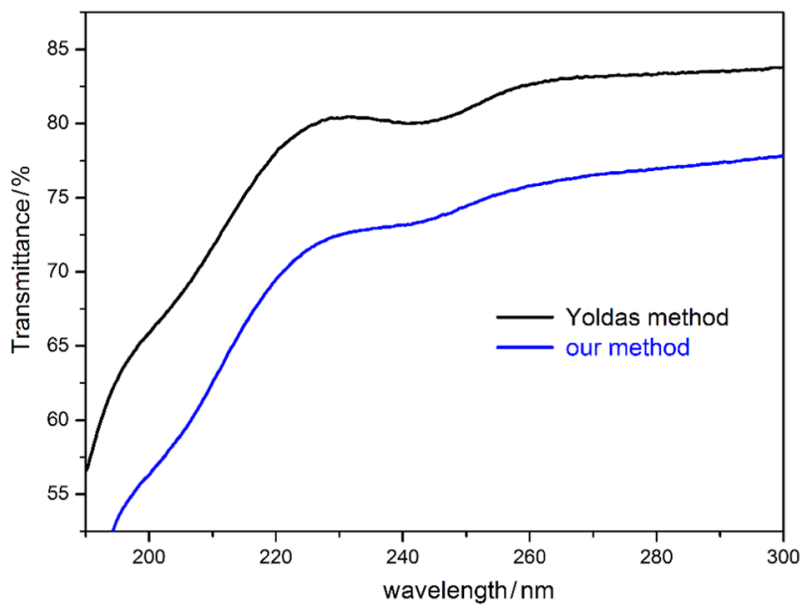

Fig. 20 Transmittance of sol-gel derived layers prepared by Yoldas and our methods from $\mathrm{Al}$ isopropoxide

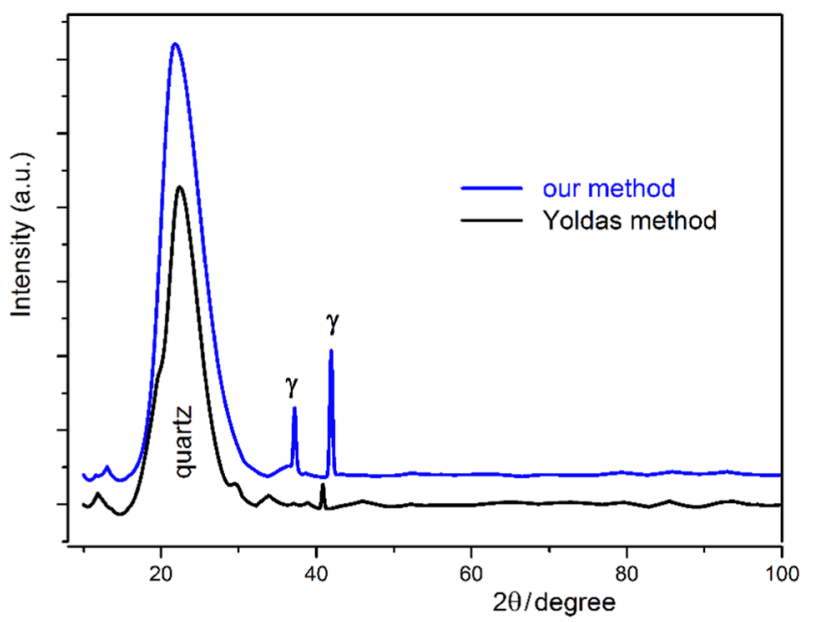

Fig. 21 GIXRD spectrum of sol-gel derived $\mathrm{Al}_{2} \mathrm{O}_{3}$ layers prepared by Yoldas and our methods from $\mathrm{Al}$ isopropoxide

\section{Conclusions}

The aim of present research work was to improve the structural and optical properties of the transparent $\gamma-\mathrm{Al}_{2} \mathrm{O}_{3}$ thin film. The investigation focused on the transparency of films and the control of perfect layer formation. The importance of gamma crystalline phase and transparency is given by the application of $\mathrm{Al}_{2} \mathrm{O}_{3}$ as a protective or absorbent layer in environmental protection. Various synthesis routes have been newly developed for layer preparation, which are based on colloidal technique and sol-gel chemistry. Many types of starting materials ( $\mathrm{Al}$ acetate, nitrate isopropoxide, boehmite, and $\mathrm{Al}_{2} \mathrm{O}_{3}$ powders) and additives ( $\mathrm{HAc}, \mathrm{HCl}, \mathrm{HNO}_{3}$, citric acid) were used in the experiments. All films were deposited on a quartz substrate by dip-coating process and heat treated at $600{ }^{\circ} \mathrm{C}$. The layers were compared with GIXRD, SEM, and UV-Visible spectroscopy. 
Fig. 22 SEM images. Upper layers were prepared by Yoldas method from $\mathrm{Al}$ isopropoxide. Lower layers were produced by our sol-gel technique from Al isopropoxide. Magnification upper: $\times 25,000 ; \times 100,000$, $\times 120,000$; lower: $\times 10,000$, $\times 100,000, \times 100,000 x$

Table 1 Comparison of $\mathrm{Al}_{2} \mathrm{O}_{3}$ layers prepared by various synthesis routes
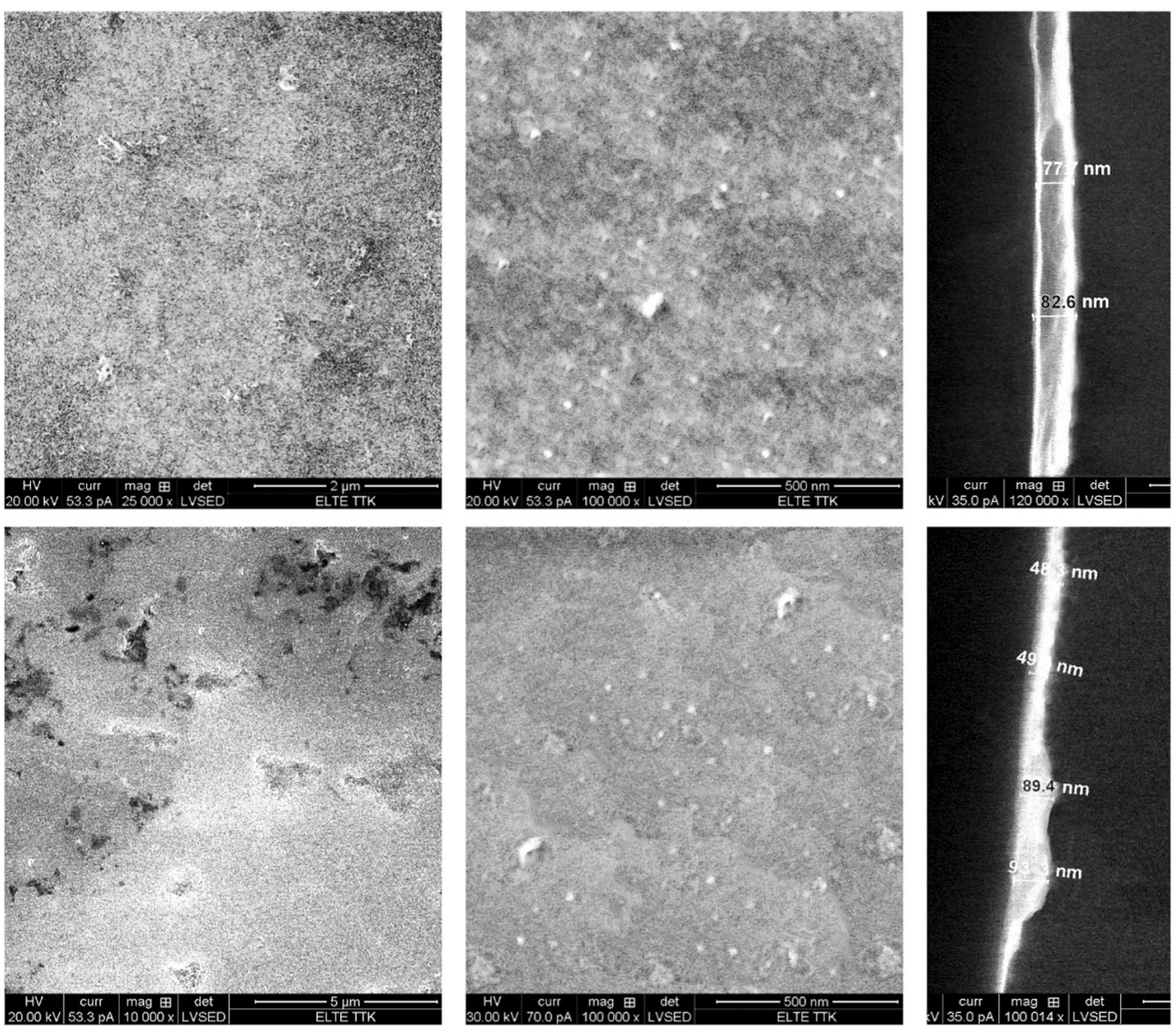

Synthesis

((precursor + additive $)$

\begin{tabular}{llll}
\hline Boehmite $(0.5 \mathrm{mr} \mathrm{HAc})$ & 90.1 & $110-120$ & Good \\
$\mathrm{Al}_{2} \mathrm{O}_{3}$ & 67.7 & $135-145$ & Moderate \\
$\mathrm{AlAc}(\mathrm{NaOH}+10 \mathrm{mr} \mathrm{HAc})$ & 86.6 & $60-105$ & Good \\
$\mathrm{AlAc}(\mathrm{NaOH}+2 \mathrm{mr} \mathrm{HCl})$ & 81.8 & $130-150$ & Moderate \\
$\mathrm{AlAc}(\mathrm{NaOH}+$ boehmite $+\mathrm{HAc})$ & 90.3 & $50-60$ & Excellent \\
$\mathrm{Al}$ nitrate $(20 \times$ water $)$ & 90.3 & $55-65$ & Excellent \\
$\mathrm{AliPr}$ (our synthesis) & 75.1 & $45-100$ & Moderate \\
AliPr (Yoldas synthesis) [27] & 81.8 & $75-85$ & Excellent \\
German commercial product & 85.3 & $130-170$ & Excellent \\
Japanese commercial product & 72.9 & - & Good \\
\hline
\end{tabular}

AlAc basic $\mathrm{Al}$ acetate, $H A c$ acetic acid, $m r$ molar ratio to $\mathrm{Al}, x$ mass ratio of water to dried gel, AliPr $\mathrm{Al}$ isopropoxide
Comparison of the colloidal suspensions (sol or slurry) with gel-like systems as precursors for layer creation has verified the application of gel-like systems results in better layers quality. The 3D network of the gel systems ensures the formation of a continuous film and allows the exact regulation of the layers thickness. The suspensions yield often thicker and not perfect layers due to their larger particles.

The best quality of layer ( $\sim 90 \%$ transmittance, $50-60 \mathrm{~nm}$ thickness, perfect covering) has been achieved by sol-gel technique starting from $\mathrm{Al}$ nitrate or $\mathrm{Al}$ acetate. The use of Al nitrate results in a nanolayer with extremely smooth surface and the layer keeps its transmittance over $80 \%$ after a $500 \mathrm{~h}$ application.

Acknowledgements This study has been supported by OTKA $\mathrm{K}$ 115259 fund. This work was completed in the ELTE Institutional Excellence Program (1783-3/2018/FEKUTSRAT) supported by the Hungarian Ministry of Human Capacities. Open access funding provided by Eötvös Loránd Eötvös University (ELTE). 


\section{Compliance with ethical standards}

Conflict of interest The authors declare that they have no conflict of interest.

Publisher's note Springer Nature remains neutral with regard to jurisdictional claims in published maps and institutional affiliations.

Open Access This article is distributed under the terms of the Creative Commons Attribution 4.0 International License (http://crea tivecommons.org/licenses/by/4.0/), which permits unrestricted use, distribution, and reproduction in any medium, provided you give appropriate credit to the original author(s) and the source, provide a link to the Creative Commons license, and indicate if changes were made.

\section{References}

1. Ao Y, Yang Y, Yuan S, Hu H, Gu H, Chen G (2007) Nanosized $\gamma$ $\mathrm{Al}_{2} \mathrm{O}_{3}$ protective film for fluorescent lamps. Ceram Int 33:1547-1550

2. Dörre E, Hübner H (1984) Alumina, Processing, properties, and applications. Springer-Verlag, New York

3. Bunshah RF (1994) Handbook of deposition technologies for films and coatings. Noyes Publications, New Jersey

4. Shamala KS, Murthy LCS, Rao KN (2004) Studies on optical and dielectric properties of $\mathrm{Al}_{2} \mathrm{O}_{3}$ thin films prepared by electron beam evaporation and spray pyrolysis method. Mater Sci Eng B Solid-State Mater Adv Technol 106:269-274

5. Balakrishnan G, Kuppusami P, Sundari ST, Thirumurugesan R, Ganesan V, Mohandas E, Sastikumar D (2010) Structural and optical properties of $\gamma$-alumina thin films prepared by pulsed laser deposition. Thin Solid Films 518:3898-3902

6. Lazar AM, Yespica WP, Marcelin S, Pébère N, Samélor D, Tendero C, Vahlas C (2014) Corrosion protection of 304 L stainless steel by chemical vapor deposited alumina coatings. Corros Sci 81:125-131

7. Díaz B, Härkönen E, Światowska J, Maurice V, Seyeux A, Marcus P, Ritala M (2011) Low-temperature atomic layer deposition of $\mathrm{Al}_{2} \mathrm{O}_{3}$ thin coatings for corrosion protection of steel: Surface and electrochemical analysis. Corros Sci 53:2168-2175

8. Gupta VK, Agarwal S, Saleh TA (2011) Synthesis and characterization of alumina-coated carbon nanotubes and their application for lead removal. J Hazard Mater 185:17-23

9. Hwang Y, Heo K, Chang CH, Joo MK, Ree M (2006) Synchrotron $\mathrm{X}$-ray reflectivity study of high dielectric constant alumina thin films prepared by atomic layer deposition. Thin Solid Films 510:159-163

10. Blittersdorf $\mathrm{S}$, Bahlawane N, Kohse-Höinghaus K, Atakan B, Müller $\mathrm{J}$ (2003) CVD of $\mathrm{Al}_{2} \mathrm{O}_{3}$ thin films using aluminum triisopropoxide. Chem Vap Depos 9:194-198

11. Maruyama T, Nakai T (1991) Aluminum oxide thin films prepared by chemical vapor deposition from aluminum 2-ethylhexanoate. Appl Phys Lett 58:2079-2080

12. Cibert C, Hidalgo H, Champeaux C, Tristant P, Tixier C, Desmaison J, Catherinot A (2008) Properties of aluminum oxide thin films deposited by pulsed laser deposition and plasma enhanced chemical vapor deposition. Thin Solid Films 516:1290-1296

13. Kohara T, Tamagaki H, Ikari Y, Fujii H (2004) Deposition of $\alpha-$ $\mathrm{Al}_{2} \mathrm{O}_{3}$ hard coatings by reactive magnetron sputtering. Surf Coat Technol 185:166-171

14. Aguilar-Frutis M, Garcia M, Falcony C, Plesch G, JimenezSandoval S (2001) A study of the dielectric characteristics of aluminum oxide thin films deposited by spray pyrolysis from $\mathrm{Al}$ (acac) $)_{3}$. Thin Solid Films 389:200-206

15. Pandey M, Tyagi K, Mishra P, Saha D, Sengupta K, Islam SS (2012) Nanoporous morphology of alumina films prepared by sol-gel dip coating method on alumina substrate. J Sol-Gel Sci Technol 64:282-288

16. Hench LL, West JK (1990) The sol-gel process. Chem Rev 90:33-72

17. Jing C, Zhao X, Zhang Y (2007) Sol-gel fabrication of compact, crack-free alumina film. Mater Res Bull Mater Res Bull 42:600-608

18. Yoldas BE (1973) Hydrolysis of aluminium alkoxides and bayerite conversion. J Appl Chem Biotechnol 23:803-809

19. Macêdo MIF, Osawa CC, Bertran CA (2004) Sol-gel synthesis of transparent alumina gel and pure gamma alumina by urea hydrolysis of aluminum nitrate. J Sol-Gel Sci Technol 30:135-140

20. Tokudome Y, Fujita K, Nakanishi K, Miura K, Hirao K (2007) Synthesis of monolithic $\mathrm{Al}_{2} \mathrm{O}_{3}$ with well-defined macropores and mesostructured skeletons via the sol-gel process accompanied by phase separation. Chem Mater 19:3393-3398

21. Kobayashi Y, Ishizaka T, Kurokawa Y (2005) Preparation of alumina films by the sol-gel method. J Mater Sci 40:263-283

22. Fu Q, Cao CB, Zhu HS (1999) Preparation of alumina films from a new sol-gel route. Thin Solid Films 348:99-102

23. Olding T, Sayer M, Barrow D (2001) Ceramic sol-gel composite coatings for electrical insulation. Thin Solid Films 398-399:581-586

24. Chandradass J, Balasubramanian M (2006) Sol-gel processing of alumina fibres. J Mater Process Technol 173:275-280

25. Kozodoy RL, Harrington JA (1995) Sol-gel alumina coating for hollow waveguide delivery of $\left.\mathrm{CO}_{2}\right)$ laser radiation. Appl Opt 34:7840-7849

26. Vanbesien K, De Visschere P, Smet PF, Poelman D (2006) Electrical properties of $\mathrm{Al}_{2} \mathrm{O}_{3}$ films for TFEL-devices made with sol-gel technology. Thin Solid Films 514:323-328

27. Toney F, Gijo J, Siby M, Rejikumar PR, Unnikrishnan NV (2007) An ultra-low hydrolysis sol-gel route for titanosilicate xerogels and their characterization. J Sol-Gel Sci Technol 41:163-168

28. Ismail AA, Ibrahim IA (2008) Impact of supercritical drying and heat treatment on physical properties of titania/silica aerogel monolithic and its applications. Appl Catal A Gen 346:200-205

29. Zhai J, Zhang L, Yao X (1999) Effects of composition and temperature on gel-formed $\mathrm{TiO}_{2} / \mathrm{SiO}_{2}$ films. J Non Cryst Solids 260:160-163

30. Chandradass J, Bae DS (2008) Synthesis and characterization of alumina nanoparticles by Igepal CO-520 stabilized reverse micelle and sol-gel processing. Mater Manuf Process 23:494-498 